\title{
Pessoal Ocupado e Jornada de Trabalho: Uma Releitura da Evolução da Produtividade no Brasil*
}

\author{
Fernando de Holanda Barbosa Filho ${ }^{\dagger}$, Samuel de Abreu Pessôa ${ }^{\ddagger}$
}

\author{
Conteúdo: 1. Introdução; 2. Dados; 3. Metodologia; 4. Resultados; 5. Conclusão. \\ Palavras-chave: Crescimento econômico, Horas trabalhadas, Produtividade do trabalho, \\ Produtividade total dos fatores. \\ Códigos JEL: $\quad$ 047; J24; J31.
}

Esse artigo recalcula a evolução da produtividade do trabalho e da produtividade total dos Fatores (PTF) no Brasil entre os anos de $1982 \mathrm{e}$ 2012 usando uma série de horas trabalhadas em vez da série de pessoal ocupado. Para tanto, utilizamos dados da PNAD e da PME para construir uma série mensal de horas trabalhadas que compatibilizasse as mudanças metodológicas da PNAD e da PME. A comparação da série de horas trabalhadas com a de pessoal ocupado revela a redução da jornada de trabalho no Brasil, fenômeno consistente em todo o período de análise e que impacta a produtividade. Com isso, a utilização de uma série de horas trabalhadas possibilita uma releitura da evolução da produtividade nas últimas três décadas no Brasil. Em particular, mostramos que a perda da produtividade do trabalho ( $-0,6 \%$ a.a) ocorrida entre os anos de 1982 e 1992 é explicada pela redução da jornada de trabalho média $(-0,7 \%)$ da economia brasileira. Os resultados indicam que, no período 1982-2012, tanto a produtividade do trabalho $(35,8 \%)$ quanto a PTF (16,3\%) apresentaram uma elevação superior à sugerida por boa parte da literatura sobre o tema baseada em séries de pessoal ocupado.

The paper computes the labor productivity and total factor productivity using a series of hours worked from 1982 to 2012. In order to do that we use a methodology that enables us to combine PNAD and PME data despite their

\footnotetext{
*Os autores agradecem os comentários e sugestões de Ana Luiza Neves de Holanda Barbosa, Armando Castelar, Edmar Bacha, Fernando Veloso, Fernando de Holanda Barbosa, Pedro Cavalcanti, Régis Bonelli, e de participantes dos seminários do IBRE, IPEA e do encontro CAEN-EPGE. Os autores agradecem Paulo Henrique Peruchetti pela assistência na pesquisa. Os autores agradecem ao Instituto Nacional de Ciência e Tecnologia do Conselho Nacional de Desenvolvimento Científico e Tecnológico (INCT/CNPq) e à Fundação de Amparo à Pesquisa do Estado do Rio de Janeiro (FAPERJ) pelo auxílio financeiro.

† Centro de Desenvolvimento Econômico (CDE) do IBRE-FGV.

${ }^{\ddagger}$ Centro de Desenvolvimento Econômico (CDE) do IBRE-FGV.
} 
methodological changes in the period 1982 to 2012, to construct a series of monthly labor hours worked. The comparison between people occupied and labor hours reveals a decrease in weekly labor hours, a phenomenon which is consistent during the whole period of analysis. This result allows us to reinterpret Brazilian productivity over the last three decades providing a different analysis of its evolution. We show that labor productivity losses $(-0.6 \%)$ between 1982 and 1992 were the result of fewer hours worked per week/worker (-0.7\%) while labor hour productivity was almost constant $(+0.1 \%)$. The results show that labor productivity was underestimated by $35.8 \%$ in the period 1982-2012 while TFP was underestimated by $16.3 \%$.

\section{INTRODUÇÃO}

O presente trabalho contribui para a literatura de duas formas distintas. Em primeiro lugar, calculamos a evolução da produtividade do trabalho e da produtividade total dos Fatores (PTF) entre os anos de 1982 e 2012 com base em uma série de horas trabalhadas em vez da série de pessoal ocupado. Para tanto, utilizamos dados da PNAD e da PME para construir uma série mensal de horas trabalhadas para a economia brasileira. A metodologia incorpora as modificações metodológicas da PNAD de $1992^{1}$ e de 2004. ${ }^{2}$ Com base nas horas trabalhadas da PNAD, utilizamos os dados da PME para construir uma série mensal de horas que leva em conta os ciclos econômicos, permitindo uma análise mais precisa da evolução da produtividade do trabalho e da produtividade total de fatores (PTF) no período. Devido a mudanças metodológicas nas principais pesquisas do Instituto Brasileiro de Geografia e Estatística (IBGE), não existe uma série de horas trabalhadas que seja comparável em todo o período de análise. ${ }^{3}$ $O$ trabalho preenche esta lacuna na literatura.

Ao longo de todo o período em estudo observa-se redução da jornada de trabalho. Portanto, os estudos que empregam a população ocupada como medida de emprego do fator trabalho superestimam a queda da produtividade. ${ }^{4}$

A década de 1980, que trouxe o fim do ciclo econômico de expansão vivido nos anos 1970, tornou-se conhecida como a "década perdida". Tal referência se deu em virtude da forte retração na produção industrial e das baixas taxas de crescimento econômico no período. São vários os estudos que reportam uma redução significativa na PTF nessa década para a economia brasileira (Bonelli e Fonseca, 1998, Gomes et alii, 2003, Ferreira e Rossi, 2003). A principal explicação para a queda da PTF no período é dada pelo elevado investimento, que não foi acompanhado por um crescimento econômico. Um resultado ainda mais significativo refere-se à queda da produtividade do trabalho (Bonelli, 2002, Ferreira e Rossi, 2003, Ellery Jr. e Teixeira, 2013). De forma geral, tais estudos sugerem queda da produtividade do trabalho na década de 1980, sugerindo também uma redução da produtividade por hora do trabalho.

Como consequência da redução da jornada de trabalho, a segunda contribuição do artigo é permitir releitura da queda da produtividade do trabalho na década de 1980. O artigo documenta que, nas décadas de 1980 e 1990, a produtividade do trabalho e a PTF foram superiores ao que usualmente se reporta na literatura sobre o tema, com a jornada de trabalho tendo papel fundamental nesta evolução.

\footnotetext{
${ }^{1}$ A PNAD de 1992 modificou a definição de trabalho e incluiu parcelas importantes de trabalhadores na série de pessoal ocupado.

${ }^{2}$ A PNAD de 2004 incluiu a área rural da região norte do Brasil.

${ }^{3}$ Houve mudança metodológica da Pesquisa Mensal de Emprego (PME) em 2002 e não há série de horas trabalhadas mensais entre 1982 e 2012.

${ }^{4} \mathrm{~A}$ redução da jornada de trabalho faz com que uma expansão do pessoal ocupado de $1 \%$, por exemplo, corresponda a uma evolução do total de horas trabalhadas inferior a $1 \%$. Nesse caso, a produtividade calculada com base no pessoal ocupado estará subestimando a produtividade da economia.
} 
Com relação à década de 2000 , esse resultado perde força em virtude de uma jornada de trabalho mais estável no período. Em particular, a redução da jornada média de trabalho ( $-0,7 \%$ a.a.) ocorrida no período reverte o resultado obtido por inúmeros estudos de que houve queda de produtividade do trabalho. Dado que a produtividade por trabalhador ocupado seguindo nossos cálculos reduziu-se à taxa de $0,6 \%$ a.a., a produtividade hora do trabalho ficou estagnada ( $+0,1 \%$ a.a.). Adicionalmente, nosso resultado de queda de $0,6 \%$ a.a. da produtividade por trabalhador ocupado é menos acentuado do que em estudos anteriores em função da correção que fizemos ao encadear a PNAD de 1990 com a de 1992.

Além desta introdução, este trabalho tem mais quatro seções. A seção 2 apresenta a base de dados utilizada no artigo. A metodologia utilizada na análise, incluindo o procedimento de construção da série de horas trabalhadas, é apresentada na terceira seção. Ainda nesta seção, apresentamos as formas de cálculo da produtividade do trabalho (PT), da Produtividade Total dos Fatores (PTF), e os métodos de decomposição do crescimento do produto. A seção 4 apresenta os resultados obtidos e a seção 5 sumariza as principais conclusões do artigo.

\section{DADOS}

As bases de dados desse trabalho englobam três pesquisas conduzidas pelo Instituto Brasileiro de Geografia e Estatística (IBGE): a Pesquisa Mensal de Empregos (PME), a Pesquisa Nacional por Amostra de Domicílios (PNAD) e o Sistema de Contas Nacionais (SCN), para o período 1982-2012.

A PNAD, conduzida pelo IBGE desde 1967, é uma pesquisa anual que cobre todo o território nacional ${ }^{5}$ trazendo informações diversas sobre características demográficas e socioeconômicas da população e características dos domicílios. ${ }^{6}$ Tal pesquisa vem sofrendo uma série de aprimoramentos e revisões ao longo dos anos. Na revisão implementada em 1992, as principais mudanças ocorreram em torno do tema trabalho. A definição de população ocupada foi ampliada. Para captar determinados grupos de pessoas envolvidas em atividade econômica que, anteriormente, não eram incluídas na população ocupada, o conceito de trabalho tornou-se mais abrangente. ${ }^{7}$ Assim, o conceito de ocupação passou a abranger o trabalho na produção para o próprio consumo exercido em atividade do ramo agrícola e o trabalho na construção para o próprio uso. Além disso, a PNAD incorporou o trabalho não remunerado, independentemente do número de horas que era exercido. Como até o ano de 1990 o trabalho não remunerado só era considerado quando fosse exercido por pelo menos 15 horas, houve grande expansão do pessoal ocupado na PNAD realizada em 1992, com relação à PNAD de 1990, e uma queda abrupta da jornada de trabalho.

O presente trabalho faz um ajuste ao excluir os trabalhadores não remunerados que trabalham menos de 15 horas por semana para as PNADs a partir de 1992. Portanto, cabe assinalar que a definição de população ocupada utilizada neste trabalho se relaciona com os indivíduos que exerceram trabalho remunerado na semana de referência, os que exerceram trabalho não remunerado nessa mesma semana por pelo menos 15 horas e os que tiveram trabalho remunerado do qual estavam temporariamente afastados. Os indivíduos que exerceram trabalho para o próprio consumo ou na construção para uso próprio, inferior a 15 horas semanais, não foram considerados como ocupados. Adicionalmente, a partir de 2004 excluímos os dados da área rural da região Norte, incluídos na PNAD a partir desse ano.

\footnotetext{
${ }^{5} \mathrm{~A}$ área rural da região norte somente foi incluída a partir de 2004.

${ }^{6}$ A Pesquisa Nacional por Amostra de Domicílios teve início no segundo trimestre de 1967, sendo os seus resultados apresentados com periodicidade trimestral, até o primeiro trimestre de 1970. A partir de 1971 os levantamentos passaram a ser anuais com realização no último trimestre. A pesquisa foi interrompida para a realização dos Censos Demográficos de 1970, 1980 e 1991. Em 1974/1975, foi levada a efeito uma pesquisa especial, denominada Estudo Nacional da Despesa Familiar - ENDEF, que, além dos temas anteriores, investigou consumo alimentar e orçamentos familiares. Durante a realização do ENDEF o levantamento básico da PNAD foi interrompido. Em 1994, por razões excepcionais, não foi realizado o levantamento da PNAD (http://www.ibge.gov.br).

${ }^{7}$ Para mais detalhes acerca das mudanças de metodologia da PNAD ver Guerra (1997).
} 
Como já exposto na Introdução, uma das principais contribuições deste trabalho é a construção de uma série mensal de horas de trabalho para a economia brasileira para o período 1982-2012. Para tanto, utilizamos metodologia semelhante à utilizada em Barbosa Filho e de Abreu Pessôa (2009) e tomamos como base os dados da PNAD que possuem abrangência nacional da economia brasileira no mês de setembro. Logo, a série de horas trabalhadas construída neste trabalho reproduz nos meses de Setembro os dados da PNAD. Além disso, o desenvolvimento de uma série de horas trabalhadas com a utilização da variação mensal das horas trabalhadas geradas pela PME permite uma mensuração mais precisa dos ciclos econômicos de cada ano, o que aprimora a análise da produtividade em curtos períodos de tempo.

A PME, iniciada na década de 1980, produz indicadores mensais sobre a força de trabalho, permitindo uma análise sobre as flutuações e tendência, a médio e longo prazo do mercado de trabalho. As informações da pesquisa se referem à condição de atividade econômica, condição de ocupação, rendimentos dos trabalhadores, posição na ocupação, entre outras, tendo como unidade amostral os domicílios. A PME tem como abrangência geográfica as seguintes regiões metropolitanas: Recife, Salvador, Belo Horizonte, Rio de Janeiro, São Paulo e Porto Alegre. Portanto, se por um lado, a PME tem periodicidade mensal, permitindo uma análise mais precisa de flutuações e tendências, por outro, sua abrangência geográfica não abarca o território nacional e não reflete de forma efetiva o que ocorre com as áreas rurais, por exemplo.

Assim como a PNAD, a PME passou por uma série de revisões metodológicas, sendo que uma das principais ocorreu no ano de 2001. Uma das principais alterações no processo de revisão da PME, neste ano, referiu-se às mudanças conceituais no tema trabalho. Dessa forma, os dados da PME, a partir de 2002, não tornam os dados comparáveis com os obtidos em anos anteriores. Parte importante desse trabalho reside em "compatibilizar" os dados anteriores e posteriores a mudança metodológica de forma a gerar uma série de horas única.

A série de horas da nova metodologia da PME se inicia em Março de 2002. A série de horas da metodologia antiga foi obtida entre Janeiro de 1991 e Fevereiro de 2003. Logo, a extensão da série de horas entre janeiro de 1991 e Março de 2002 é realizada através da incorporação da variação mensal ocorrida de forma anterior a Março de 2002.

A série de horas trabalhadas da PME com a metodologia nova (a partir de Março de 2002) e a antiga (entre janeiro 1991 e fevereiro de 2003) foi obtida diretamente do site do IBGE. ${ }^{8}$ Para o período anterior a 1991, não encontramos uma série de horas trabalhadas. Desta forma, utilizamos a série de pessoal ocupado como uma proxy para a série de horas trabalhadas, obtida no site do Instituto de Pesquisa Econômica Aplicada (IPEADATA). Os erros ocasionados pelo uso dessa proxy acabam em Setembro de cada ano quando se utiliza a PNAD para corrigir o nível da série de horas.

Para o cálculo da produtividade do trabalho e da produtividade total dos fatores utilizamos as séries de PIB, Formação Bruta de Capital Fixo, deflator implícito do PIB e deflator da Formação Bruta de Capital Fixo do IBGE entre 1982 e 2012 disponíveis no site do IPEADATA, ${ }^{9}$ deflacionado todos os valores para o ano de 2012. Por último, utilizamos a série do Nível de Utilização da Capacidade Instalada (NUCI) da Fundação Getúlio Vargas (FGV) para o mesmo período. ${ }^{10}$

A seção seguinte apresenta de forma mais detalhada como se deu a construção da série de horas trabalhadas, da jornada de trabalho, da produtividade do trabalho e da produtividade total dos fatores.

\footnotetext{
${ }^{8}$ http://www.ibge.gov.br/home/estatistica/indicadores/trabalhoerendimento/pme_nova/default.shtm..

${ }^{9}$ http://www.ipeadata.gov.br/.

${ }^{10}$ http://www.antigofgvdados.fgv.br/.
} 


\section{METODOLOGIA}

\subsection{Série de Horas Trabalhadas}

O total de horas trabalhadas para os meses de setembro de cada ano foi obtido pelo seguinte cálculo: soma do total de horas trabalhadas de todos os indivíduos remunerados e não remunerados com jornadas de pelo menos 15 horas de trabalho, e expansão das mesmas pelo peso de cada observação (peso da pessoa). A variável Horas $_{P N A D, 09 / t}$ descreve o total de horas trabalhadas no Brasil no mês de setembro do ano $t$, e é obtida da seguinte forma:

\subsubsection{Nível da Série}

$$
\operatorname{Horas}_{P N A D, 09 / t}=\sum_{i=1}^{N} p_{i} H T_{i}
$$

onde $p_{i}$ é o peso do indivíduo na amostra e $H T_{i}$ é o total de horas trabalhadas pelo indivíduo em setembro do ano $t$.

\subsubsection{Variações Mensais}

A série mensal de horas, $\operatorname{Horas}_{P M E, t}$, é encadeada entre 1991 e 2012 conforme a equação abaixo:

$$
\operatorname{Horas}_{P M E, t}=P M E_{\text {nova }, 3 / 2002} \frac{P M E_{\text {antiga },},}{P M E_{\text {antiga }, 3 / 2002}}
$$

em que $P M E_{n o v a, 3 / 2002}$ é o número índice do total de horas trabalhadas da PME nova em Março de 2002 e $\frac{P M E_{a n t i g a, t}}{P M E_{\text {antiga }, 3 / 2002}}$ é a variação da série de horas da PME antiga entre o instante $t\left(P M E_{\text {antiga }}, t\right)$ e Março de 2002 ( $P M E_{\text {antiga }, 3 / 2002}$ ). Com isso, a equação (2) inclui a variação do total de horas trabalhadas da antiga PME na nova PME.

A ausência de uma série de horas anterior a Janeiro de 1991 gera uma dificuldade adicional na expansão da série de horas para um período anterior a 1991. Para solucionar esse problema, utilizamos a série de pessoal ocupado da PME que vai de Maio de 1982 a Dezembro de 2002 como proxy para a série de horas no período. ${ }^{11}$ No entanto, essa série possui clara descontinuidade entre Dezembro de 1990 e Janeiro de 1991. Nesse intervalo de um mês ocorre uma redução no total de pessoal ocupado de $13 \% .{ }^{12}$ Para corrigir esse problema avaliamos a variação que ocorreu entre dezembro de um ano e dezembro do ano seguinte para os três anos anteriores e os três anos posteriores a 1990. A média dessa variação de $2,27 \%$ foi utilizada para corrigir a PO de Dezembro de 1990 . Com essa correção realizada, a série de Pessoal Ocupado ( $P O_{\text {antiga }}$ ) é encadeada até Maio de 1982.

Em seguida, utiliza-se a série de Pessoal Ocupado entre Maio de 1982 e Dezembro de 1990 (PO antiga $)$ para encadear a variação na série de horas trabalhadas ( or $\left._{\text {os }}{ }_{P M E, t}\right)$, conforme a equação abaixo:

$$
\operatorname{Horas}_{P M E, t}=\operatorname{Horas}_{P M E, 1 / 1991} \frac{P O_{\text {antiga }}, t}{P O_{\text {antiga }, 1 / 1991}}
$$

\footnotetext{
${ }^{11} \mathrm{~A}$ série de pessoal ocupado fornece a variação mensal do mercado de trabalho. Apesar de ser uma série de pessoal ocupado, a utilização do total de horas trabalhadas no mês de Setembro da PNAD fornece a tendência de redução da jornada de trabalho com a proxy não descaracterizando a série de horas trabalhadas.

${ }^{12}$ Apesar do péssimo desempenho da economia brasileira no ano de 1990 não é crível acreditar em um ajuste dessa magnitude no mercado de trabalho entre dois meses, Dezembro de 1990 e Janeiro de 1991.
} 
em que $\operatorname{Horas}_{P M E, t}$ é a série de horas mensais da PME no instante $t$, $\operatorname{Horas}_{P M E, 1 / 1991}$ é a série de horas mensais trabalhadas entre Janeiro de 1991 e 2012 e $\frac{P O_{a n t i g a, t}}{P O_{a n t i g a, 1 / 1991}}$ é a variação da série de pessoal ocupado entre Maio de 1982 e Janeiro de 1991.

\subsubsection{Horas Totais Trabalhadas}

Com base nos dados da PME do total de horas trabalhadas, construímos um número índice do total de horas trabalhadas com base em Maio de 1982, para captar a variação mês a mês do total de horas trabalhadas. A equação (4) descreve este índice:

$$
I_{H T P M E, m / t}=\frac{H_{H T P M E, m / t}}{H_{H T P M E, 5 / 1982}} 100
$$

em que $I_{H T P M E, m / t}$ é o índice de horas trabalhadas no mês $m$ ano $t, H_{H T P M E, m / t}$ é o total de horas trabalhadas no mês $m$ do ano $t$ e $H_{H T P M E, 5 / 1982}$ é o total de horas trabalhadas em Maio de 1982, ano base utilizado. Em seguida, associa-se o índice de horas trabalhadas obtido com base na PME, $I_{H T P M E, m / t}$, para encadear uma série a partir das horas trabalhadas obtidas na PNAD de 1982, $\widetilde{H}_{P N A D}$, conforme a equação abaixo:

$$
\widetilde{H}_{P N A D, m / t}=\widetilde{H}_{P N A D, 9 / 1982} \frac{I_{H T P M E, m / t}}{I_{H T P M E, m-1 / t}}
$$

em que $\widetilde{H}_{P N A D, m / t}$ é a série do número índice de horas trabalhadas no mês $m$ ano $t$, na qual o total de horas trabalhadas em Setembro de 1982 (mês da PNAD) é igual ao valor da PNAD e $\frac{I_{H T P M E, m / t}}{I_{H T P M E, m-1 / t}}$ é o responsável por toda a variação da série de horas entre Maio de 1982 e Dezembro de 2012.

Assim, o número de horas trabalhadas no mês $m$ do ano $t$ é obtido através do número de horas trabalhadas no mês $t-1$ multiplicado pela variação das horas trabalhadas obtida através da razão do índice de horas $\left(\frac{I_{H T P M E, m / t}}{I_{H T P M E, m-1 / t}}\right)$.

No entanto, como a variação entre Setembro do ano $t-1$ e do ano $t$ da PME é diferente da variação da PNAD, os meses de Setembro da série $\widetilde{H}_{P N A D, m / t}$ não reproduzem o mesmo valor obtido na PNAD. Com a finalidade de compatibilizar a variação mensal da PME com o número de horas totais trabalhadas obtidos na PNAD (Total de horas trabalhadas) "calibra-se" a variação do PME para o número de horas trabalhadas do mês de setembro do ano $t$ ser o mesmo obtido na PNAD do ano $t$. Para tanto, utiliza-se um termo de correção $\left(C_{R M, t}\right)$, que é a razão entre as horas da $\operatorname{PNAD}\left(H_{P N A D, t}\right)$ e as horas do mês de setembro com variação da PME $\left(\widetilde{H}_{P N A D, 9 / t}\right)$ do ano $t$ :

$$
C_{R M, t}=\frac{H_{P N A D, t}}{\widetilde{H}_{P N A D, 9 / t}}
$$

Como esse termo de correção varia com o tempo, pondera-se o número de horas totais trabalhadas da PME $\left(\widetilde{H}_{P N A D, m / t}\right)$ dando mais peso para o fator de correção mais próximo da observação:

$$
H T_{m / t}=\widetilde{H}_{P N A D, m / t}\left[\left(\frac{(09 / t+1)-(m / t)}{12}\right) C_{R M, t}-\left(1-\left(\frac{(09 / t+1)-(m / t)}{12}\right) C_{R M, t+1}\right)\right](7)
$$

$m / t \in[09 / t, 09 / t+1]$

A equação (7) acima reporta o total de horas no ano $\left(H T_{m / t}\right)$, resultante da compatibilização feita entre as séries da PME e da PNAD. 


\subsection{Jornada Média}

A série anual da jornada média de trabalho no Brasil $\left(J M_{t}\right)$ é dada pela razão entre o total de horas trabalhadas em cada ano $\left(H_{P N A D, t}\right)$ e a população ocupada do mesmo ano $\left(P O_{t}\right)$ :

$$
J M_{t}=\frac{H_{P N A D, t}}{P O_{t}}
$$

\subsection{Produtividade}

A série construída de horas trabalhadas é utilizada para construirmos uma série para a produtividade do Trabalho $(P T)$ e para a produtividade total dos fatores $(P T F)$ no Brasil.

\subsubsection{Produtividade do Trabalho}

A produtividade do trabalho $(P T)$ pode ser calculada de duas formas distintas: i) com base no total de horas trabalhadas $(H T): P T H T_{t}=\frac{P I B_{t}}{H T_{t}}$, ou ii) com base no pessoal ocupado $(P O): P T P O_{t}=$ $\frac{P I B_{t}}{P O_{t}}$. Em período de estabilidade da jornada de trabalho, a variação das duas séries é idêntica. No entanto, em períodos em que a jornada média de trabalho varia, a produtividade do trabalho é medida de forma mais precisa com base nas horas totais trabalhadas.

Com isso, a decomposição da evolução do produto $\left(P I B_{t}\right)$ pode ser realizada conforme a equação abaixo:

$$
P I B_{t}=\frac{P I B_{t}}{H T_{t}} \times \frac{H T_{t}}{P O_{t}} \times P O_{t}=P T H T_{t} \times J T_{t} \times P O_{t}
$$

o $P I B_{t}$ depende da produtividade hora do trabalhador $\left(P T H T_{t}\right)$, da jornada média de trabalho $\left(J T_{t}\right)$ e do total de pessoal ocupado $\left(P O_{t}\right)$. Com isso, variação do PIB pode ser decomposta em variação da produtividade hora do trabalho, variação da margem intensiva do trabalho e variação da margem extensiva do trabalho, conforme a equação abaixo:

$$
\frac{1}{N} \ln \left(\frac{Y_{t+N}}{Y_{t}}\right)=\frac{1}{N} \ln \left(\frac{P T P O_{t+N}}{P T P O_{t}}\right)+\frac{1}{N} \ln \left(\frac{P O_{t+N}}{P O_{t}}\right)
$$

Utilizando o fato de que a produtividade do trabalho pode ser decomposta em produtividade hora e jornada média, podemos reescrever (9) como:

$$
\frac{1}{N} \ln \left(\frac{Y_{t+N}}{Y_{t}}\right)=\frac{1}{N} \ln \left(\frac{P T H T_{t+N}}{P T H T_{t}}\right)+\frac{1}{N} \ln \left(\frac{J T_{t+N}}{J T_{t}}\right)+\frac{1}{N} \ln \left(\frac{P O_{t+N}}{P O_{t}}\right)
$$

em que $\left(\frac{P T H T_{t+N}}{P T H T_{t}}\right)$ é a variação da produtividade hora do trabalho entre $t$ e $t+N$, $\left(\frac{J T_{t+N}}{J T_{t}}\right)$ é a variação da jornada de trabalho entre $t$ e $t+N$ e $\left(\frac{P O_{t+N}}{P O_{t}}\right)$ é a variação do pessoal ocupado entre $t$ e $t+N$ 


\subsubsection{Produtividade Total dos Fatores}

A função de produção, $Y_{t}=A_{t} F\left(u_{t} K_{t}, L_{t}\right)$, utilizada nesse artigo é dada pela especificação CobbDouglas:

$$
Y_{t}=A_{t}\left(u_{t} K_{t}\right)^{\alpha} L_{t}^{1-\alpha}
$$

em que $Y_{t}$ é o produto agregado, $A_{t}$ é a produtividade total dos fatores $(P T F), u_{t} K_{t}$ é o total de serviços produtivos do capital utilizado na produção; $u_{t}$ é o índice de utilização da capacidade instalada (NUCI), $K_{t}$ é o estoque de capital físico disponível na economia, e $L_{t}$ é o fator trabalho que pode ser representado pelo número de horas por trabalhador ou pelo total de pessoal ocupado; $\alpha$ é a elasticidade do produto em relação ao capital, a qual é igual à participação do capital na renda em equilíbrio competitivo. Com base em Gomes, Pessôa e Veloso (2003), tomamos como hipótese $\alpha=0,4$.

O estoque de capital físico é calculado com base no método do inventário perpétuo, dado por:

$$
K_{t+1}=(1-\delta) K_{t}+I_{t}
$$

em que $K_{t}$ é o nível de capital inicial, $K_{t+1}$ é o nível de capital do período seguinte, $\delta$ é a taxa de depreciação e $I_{t}$ é o investimento. Seguindo, novamente, Gomes, Pessôa e Veloso(2003), adotamos como hipótese que a relação capital-produto $(K / Y)$ em 1970 era igual a 2,36 e que $\delta=3,5 \%$ a.a. Os dados de investimento $\left(I_{t}\right)$ foram obtidos da série de Formação Bruta de Capital Fixo a preços constantes do Sistema de Contas Nacionais (SCN) do IBGE. O estoque de capital foi ajustado pelo grau de utilização da capacidade, $u_{t}$, obtido a partir de dados da Fundação Getulio Vargas (FGV).

A PTF é obtida a partir da equação (10):

$$
A_{t}=\frac{Y_{t}}{\left(u_{t} K_{t}\right)^{\alpha} L_{t}^{1-\alpha}}
$$

Com base na equação (11), podemos decompor o produto para analisar a importância relativa de cada um dos fatores de produção no produto no Brasil. A evolução da decomposição do produto entre os instantes $\mathrm{t}$ e $\mathrm{t}+\mathrm{N}$ pode ser decomposta da seguinte forma:

$$
\frac{1}{N} \ln \left(\frac{Y_{t+N}}{Y_{t}}\right)=\frac{1}{N} \ln \left(\frac{A_{t+N}}{A_{t}}\right)+\alpha \frac{1}{N} \ln \left(\frac{u_{t+N} K_{t+N}}{u_{t} K_{t}}\right)+(1-\alpha) \frac{1}{N} \ln \left(\frac{L_{t+N}}{L_{t}}\right)
$$

em que $\left(\frac{A_{t+N}}{A_{t}}\right)$ é a variação da produtividade total dos fatores, $\left(\frac{u_{t+N} K_{t+N}}{u_{t} K_{t}}\right)$ é a variação do capital e $\left(\frac{L_{t+N}}{L_{t}}\right)$ é a variação do fator trabalho no período.

\section{RESULTADOS}

\subsection{Horas Trabalhadas, Pessoal Ocupado e Jornada de Trabalho}

A Figura 1 mostra que o pessoal ocupado cresceu em ritmo mais elevado do que o total de horas trabalhadas. Isto sugere que calcular a produtividade (do trabalho ou total de fatores) com base no pessoal ocupado, potencialmente, gera erro de medida. ${ }^{13}$

\footnotetext{
${ }^{13} \mathrm{~A}$ redução da jornada de trabalho ocasiona em subestimação da produtividade caso se utilize uma série de pessoal ocupado em vez de horas trabalhadas.
} 
Figura 1: Evolução do Pessoal Ocupado e das Horas Trabalhadas

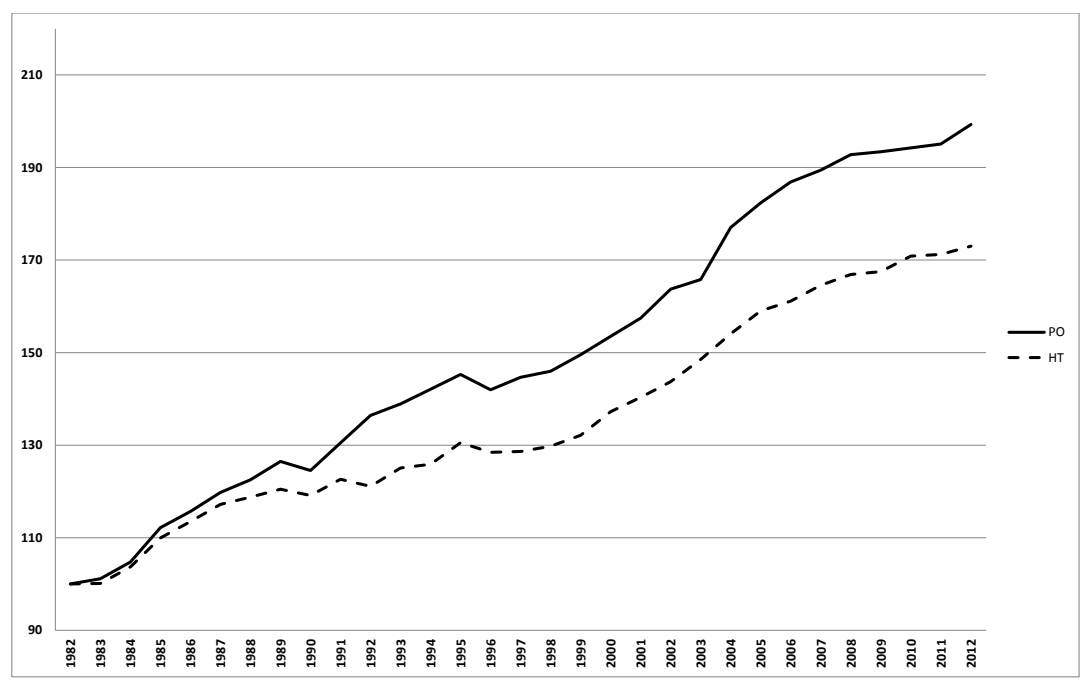

Fonte: Elaboração própria com dados da PNAD e do IBGE.

O maior crescimento do pessoal ocupado em relação ao total de horas trabalhadas no período 19822012 indica uma queda da jornada de trabalho média no Brasil. Esse fato que pode ser confirmado na Figura 2, com esse resultado sendo consistente com a evidência empírica americana que reporta uma queda na jornada de trabalho nos Estados Unidos ao longo do último século. ${ }^{14}$

Figura 2: Evolução da Jornada de Trabalho

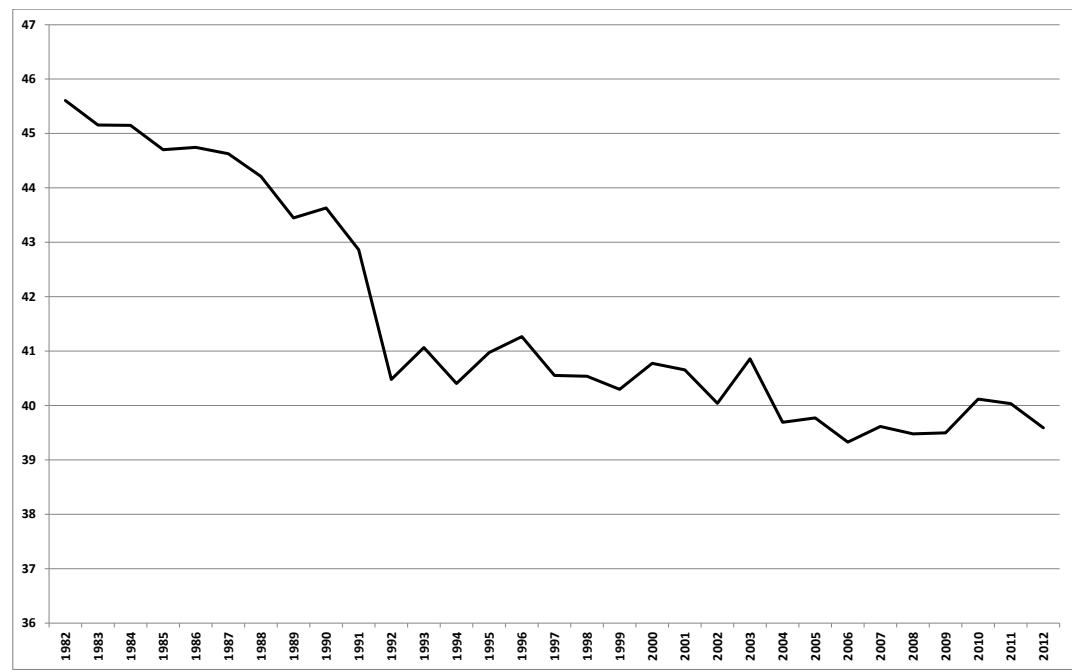

Fonte: PNAD

\footnotetext{
${ }^{14}$ Coleman e Pencavel (1993a,b) e Owen (1988) mostram uma redução da jornada para os Estados Unidos.
} 
A maior participação feminina no mercado de trabalho é um dos fatores que poderiam contribuir para a redução da jornada de trabalho média. As mulheres trabalham em média menos horas por semana do que os homens. Logo, a maior participação de mulheres na mão de obra total gera uma redução da jornada média de trabalho pelo efeito composição. ${ }^{15}$

Tabela 1: Decomposição da Redução da Jornada de Trabalho por Gênero

\begin{tabular}{cccc}
\hline & Efeito Nível & Efeito Composição & Total \\
\hline $1982-2012$ & $-4,2$ & $-0,6$ & $-4,8$ \\
& $87 \%$ & $13 \%$ & \\
$1982-1992$ & $-1,8$ & $-0,4$ & $-2,2$ \\
& $83 \%$ & $17 \%$ & \\
$1992-2002$ & $-0,7$ & $-0,2$ & $-0,9$ \\
& $75 \%$ & $25 \%$ & \\
$2002-2012$ & $-1,6$ & $-0,1$ & $-1,7$ \\
& $94 \%$ & $6 \%$ & \\
\hline
\end{tabular}

Fonte: Elaboração Própria.

No entanto, os resultados da Tabela 1 mostram que esse não é o caso. A realização da decomposição da redução da jornada de trabalho em efeito nível e composição mostra que a maior participação de mulheres no mercado de trabalho contribui com somente $12 \%$ da redução de quase 5 horas ocorrida entre 1982 e 2012. O período no qual o efeito composição possui maior capacidade de explicação (25\%) foi entre 1992 e 2002, quando a redução da jornada ocorreu em rimo mais lento (-0,9 horas). Desta forma, a Tabela 1 indica que a queda nas horas semanais trabalhadas foi determinada pela mudança no nível da jornada de trabalho.

Outro componente que afeta a jornada de trabalho média de uma economia é a composição setorial dessa. ${ }^{16}$ Caso setores com horas de trabalho semanais menores ganhem importância relativa no emprego, a jornada média da economia seria reduzida pelo efeito composição.

A Tabela 2 mostra que o efeito composição setorial na economia brasileira teria pouco impacto na redução da jornada de trabalho. No período 1982-2012 o efeito composição elevaria a jornada em 0,1 horas. Isso decorre da redução da mão-de-obra do campo perder peso relativo para o setor de serviços. Nessa transferência de recursos de agropecuária para o setor de serviços, o efeito composição desses setores se compensa.

\footnotetext{
${ }^{15}$ Pode-se escrever a jornada de trabalho como uma soma ponderada da jornada de diversos grupos $i$, conforme $J T_{t}=$ $\sum_{i} \varphi_{i, t} J T_{i, t}$, em que $\varphi_{i, t}$ é o peso relativo do grupo $i$ no emprego total e $J T_{i, t}$ é a jornada de trabalho do grupo $i$ no instante $t$. A decomposição da variação da jornada de trabalho $(J T)$ pode ser feita da seguinte forma: $J T_{t}-J T_{t-1}=\sum_{i} \frac{\varphi_{i, t}+\varphi_{i, t-1}}{2}\left(J T_{i, t}-J T_{i, t-1}\right)+\sum_{i} \frac{J T_{i, t}+J T_{i, t-1}}{2}\left(\varphi_{i, t}-\varphi_{i, t-1}\right)$

Com isso podemos separar a variação da jornada de trabalho em efeito nível $\left(\Delta J T_{t}^{N}\right)$ e efeito composição $\left(\Delta J T_{t}^{C}\right)$, conforme: $J T_{t}-J T_{t-1}=\sum_{i} \Delta J T_{i, t}^{N}+\sum_{i} \Delta J T_{i, t}^{C}=\Delta J T_{t}^{N}+\Delta J T_{t}^{C}$.

${ }^{16}$ A queda de 4,7\% da jornada de trabalho entre 1992 e 2011 no reino unido é explicada em boa parte por uma mudança estrutural da economia, na qual o setor de serviços passou a representar $80 \%$ do emprego ante $68 \%$ em 1992. Para mais detalhes ver ONS (2011).
} 
Tabela 2: Decomposição da Redução da Jornada de Trabalho por Setor

\begin{tabular}{cccc}
\hline & Efeito Nível & Efeito Composição & Total \\
\hline $1982-2012$ & $-4,8$ & 0 & $-4,8$ \\
& $101 \%$ & $-1 \%$ & \\
$1982-1992$ & $-2,1$ & $-0,1$ & $-2,2$ \\
& $96 \%$ & $4 \%$ & \\
$1992-2002$ & $-1,0$ & 0,1 & $-0,9$ \\
& $107 \%$ & $-7 \%$ & \\
$2002-2012$ & $-1,8$ & 0,1 & $-1,6$ \\
& $107 \%$ & $-7 \%$ & \\
\hline
\end{tabular}

Fonte: Elaboração Própria.

Dessa forma, mudanças na composição da mão-de-obra por gênero e modificações do peso relativo setorial no emprego explicam muito pouco da variação total da jornada de trabalho com o efeito nível sendo o principal componente para explicar sua queda.

A elevação da renda é um fator que impacta diretamente nas horas semanais trabalhadas. $\mathrm{O}$ aumento de renda faria com que houvesse um aumento gradativo da demanda por lazer reduzindo a jornada média de trabalho. Nesse sentido, elevação da tributação no Brasil com ampliação da taxação marginal no Brasil teria como impacto uma redução nas horas semanais trabalhadas na mesma linha de Prescott (2004). ${ }^{17,18}$

Alesina e Sacerdote (2006) sugerem que diferenças de regulação no mercado de trabalho e o impacto dos sindicatos são os fatores mais importantes para explicar o diferencial de jornada de trabalho entre os Estados Unidos e a Europa. Nesse, sentido, houve um efeito exógeno que alterou a regulação do trabalho e estimulou a redução da jornada de trabalho no Brasil no final da década de oitenta. A Constituição Federal de 1988 aprovou a redução da jornada de trabalho legal de 48 para 44 horas semanais (ou oito horas diárias). ${ }^{19}$ Os dados mostram que nos anos seguintes à aprovação da Constituição Federal de 1988 observa-se uma redução mais profunda da jornada de trabalho que cai mais de $8 \%$ entre 1988 (44,2 horas) e 1992 (40,5 horas). A Tabela 3 mostra o impacto da medida de redução de jornada de trabalho legal de 48 para 44 horas, implementada pela Constituição Federal de 1988, na redução da jornada de trabalho. ${ }^{20}$

\footnotetext{
${ }^{17}$ Prescott (2004) explica o diferencial de horas trabalhadas entre os Estados Unidos e a Europa devido à diferença dos sistemas tributários das duas regiões. A maior tributação europeia se refletiria em menores jornadas de trabalho.

${ }^{18}$ A carga tributária no Brasil cresceu bastante entre 1982 e 2012 e as alíquotas marginais de imposto de renda aumentaram ao longo do período.

${ }^{19}$ Gonzaga et alii (2003) mostram que as alterações da Constituição de 1988 referentes à redução da jornada de trabalho provocaram uma queda da jornada efetiva de trabalho e que tal redução não teve efeitos negativos sobre o emprego no curto prazo (nos 12 meses seguintes à mudança constitucional).

${ }^{20}$ Gonzaga et alii (2003).
} 
Tabela 3: Parcela da População Ocupada por jornada de Trabalho (em \%)

\begin{tabular}{ccccccc}
\hline & 1986 & 1987 & 1988 & 1989 & 1990 & 1992 \\
\hline Jornada Média & 45,2 & 45,1 & 44,8 & 43,9 & 43,8 & 42 \\
\hline Inferior a 36 horas & 17,28 & 19,28 & 19,37 & 19,66 & 20,23 & 26,21 \\
Entre 36 e 40 horas & 24,01 & 23,1 & 22,87 & 27,58 & 27,89 & 23,68 \\
Entre 40 e 44 horas & 4,84 & 5,79 & 9,78 & 13,14 & 12,14 & 10,74 \\
Entre 44 e 48 horas & 27,6 & 26,33 & 22,78 & 17,31 & 17,22 & 17,12 \\
Maior que 48 horas & 26,26 & 25,5 & 25,2 & 22,31 & 22,53 & 22,25 \\
\hline \multicolumn{5}{c}{ Fonte: PNAD. }
\end{tabular}

Apesar de a jornada média de trabalho de 1988 (44,8 horas) se situar próxima da determinação de uma jornada máxima de 44 horas de trabalho, os agentes ajustaram as horas trabalhadas na economia brasileira (ver Tabela 3). Esse ajuste pode ser observado na redução do percentual de pessoal ocupado que trabalhava jornadas superiores a 44 horas entre 1988 e os anos seguintes. Em 1988, 48\% do pessoal ocupado trabalhavam jornadas superiores a 44 horas semanais. A partir de 1989, essa parcela do pessoal ocupado se reduz para $39,6 \%$.

Como resultado dessa diminuição, as horas semanais trabalhadas se reduzem em 0,9 horas entre 1988 e 1989. Descontando-se a redução média da jornada de trabalho entre 1982 e $1988(0,13)$, o impacto da nova constituição entre 1988 e 1989 seria de 0,7 horas, o que explicaria um terço da redução da jornada (2,2 horas) entre 1982 e 1992.

No entanto, ao se observar a Tabela 3, percebe-se o impacto da mudança de metodologia da PNAD entre 1990 e 1992. O efeito da mudança constitucional é percebido entre 1988 e 1990 com redução dos grupos que trabalham jornadas maiores. Entretanto, a elevação de pessoas com carga horária inferior a 36 horas aumenta de forma expressiva em 1992, demonstrando o impacto da mudança na definição de trabalho da PNAD de 1992. ${ }^{21}$

O ajuste nos dados da PNAD pode ser observado na Tabela 4, que mostra os dados de pessoal ocupado, horas trabalhadas e jornada média de trabalho nos dados originais da PNAD e nos dados ajustados. Nessa Tabela, observa-se com clareza o salto entre 1990 e 1992 . O pessoal ocupado, cresce 9,2\% em dois anos, sendo esse um período de recessão. Os dados originais mostram, ainda, uma expansão das horas de $4,7 \%$ e redução da jornada de 1,8 horas $(43,8$ menos 42,0$)$. 0 ajuste dos dados faz com que o crescimento do pessoal ocupado seja mais modesto, ou seja, $4,9 \%$, e que o aumento do total de horas seja de somente 3,9\% além de mostrar uma queda da jornada de somente 0,4 horas (43,8 menos 43,4 horas). Com isso, o ajuste parece corrigir de forma satisfatória a mudança metodológica do período.

\footnotetext{
${ }^{21}$ A PNAD de 1992 incluiu trabalhadores não remunerados com jornada de trabalho inferior a 15 horas.
} 
Tabela 4: Dados Originais e Ajustados da PNAD

\begin{tabular}{|c|c|c|c|c|c|c|}
\hline \multicolumn{4}{|c|}{ Dados Originais da PNAD } & \multicolumn{3}{|c|}{ Dados Ajustados da PNAD } \\
\hline & \multicolumn{2}{|c|}{ Pessoal Ocupado } & Jornada & \multicolumn{2}{|c|}{ Pessoal Ocupado } & Jornada \\
\hline 1988 & \multicolumn{2}{|c|}{58.641 .269} & 44,8 & \multicolumn{2}{|l|}{58.641 .269} & 44,8 \\
\hline 1989 & \multicolumn{2}{|l|}{60.538 .010} & 43,9 & \multicolumn{2}{|l|}{60.538 .010} & 43,9 \\
\hline 1990 & \multicolumn{2}{|l|}{59.632 .463} & 43,8 & \multicolumn{2}{|l|}{59.632 .463} & 43,8 \\
\hline 1992 & \multicolumn{2}{|l|}{65.117 .462} & 42,0 & \multicolumn{2}{|l|}{62.531 .168} & 43,4 \\
\hline \multicolumn{7}{|c|}{ Número Índice } \\
\hline & \multicolumn{3}{|c|}{ Dados Originais da PNAD } & \multicolumn{3}{|c|}{ Dados Ajustados da PNAD } \\
\hline & Pessoal Ocupado & Horas & Jornada & Pessoal Ocupado & Horas & Jornada \\
\hline 1988 & 100 & 100 & 100 & 100 & 100 & 100 \\
\hline 1989 & 103,2 & 101 & 97,8 & 103,2 & 101 & 97,8 \\
\hline 1990 & 101,7 & 99,4 & 97,8 & 101,7 & 99,4 & 97,8 \\
\hline 1992 & 111 & 104 & 93,7 & 106,6 & 103,3 & 96,9 \\
\hline
\end{tabular}

O ajuste mensal das séries é importante, pois inclui o ciclo econômico intra-anual em vez de focar a análise em somente um mês (Setembro, no caso da PNAD) que pode ser um mês bom ou ruim na economia. Dessa forma, a Tabela 5 compara os dados ajustados da PNAD com os mensais ajustados.

Tabela 5: Dados Ajustados e Ajustados Mensais da PNAD

\begin{tabular}{|c|c|c|c|c|c|c|}
\hline \multicolumn{7}{|c|}{ Número Índice } \\
\hline & \multicolumn{3}{|c|}{ Dados Ajustados da PNAD } & \multicolumn{3}{|c|}{ Dados Ajustados Mensais da PNAD } \\
\hline & Pessoal Ocupado & Horas & Jornada & Pessoal Ocupado & Horas & Jornada \\
\hline 1988 & 100,0 & 100,0 & 100,0 & 100,0 & 100,0 & 100,0 \\
\hline 1989 & 103,2 & 101,0 & 97,8 & 102,5 & 100,8 & 98,3 \\
\hline 1990 & 101,7 & 99,4 & 97,8 & 102,0 & 99,3 & 97,3 \\
\hline 1992 & 106,6 & 103,3 & 96,9 & 104,9 & 102,2 & 97,5 \\
\hline
\end{tabular}

A comparação dos dados ajustados e ajustados mensais mostra que a evolução do pessoal ocupado entre 1990 e 1992, em termos mensais, foi superior em 2,9\%, evolução similar a das hooras trabalhadas, resultado mais consistente com um PIB que cresceu somente 0,6\% entre 1990 e 1992 . Com isso, a redução da jornada de trabalho é de 2,5\% no período 1988-1992.

A Figura 3 mostra a jornada de trabalho no Brasil com base nos dados originais da PNAD e com o ajuste para as mudanças metodológicas de 1992 e 2004 . Essa apresenta redução até meados dos anos 2000, quando passa a apresentar estabilidade. A grande queda ocorrida entre 1990 e 1992 deixa de 
existir uma vez que no ajuste realizado retirou-se da amostra o enorme contingente de trabalhadores que foram incluídos em $1992 .{ }^{22}$

Figura 3: Evolução da Jornada de Trabalho

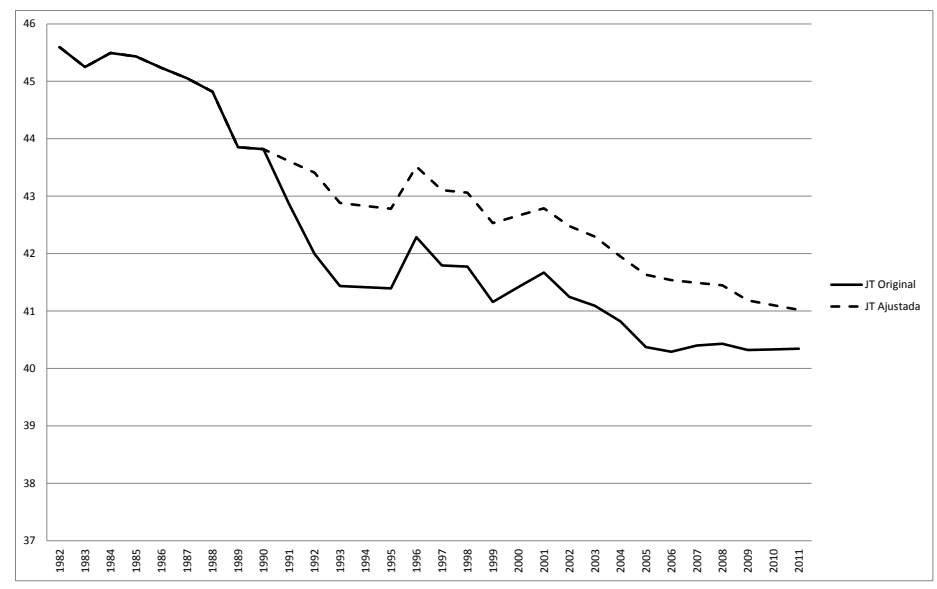

Fonte: Elaboração Própria.

A Figura 4 mostra, em número índice, as três séries distintas (original da PNAD, PNAD ajustada pelas mudanças metodológicas e PNAD ajustada mensal) de pessoal ocupado. A figura mostra que os dados originais estão inflados, principalmente entre 1982 e 1992 . A utilização dos dados mensais na série ajustada mostra que o ajuste mensal reduz o nível da série de forma discreta. Ou seja, para análises de longo prazo o ganho do ajuste mensal é pequeno, mas relevante para análises de curto prazo.

Figura 4: Séries de Pessoal Ocupado

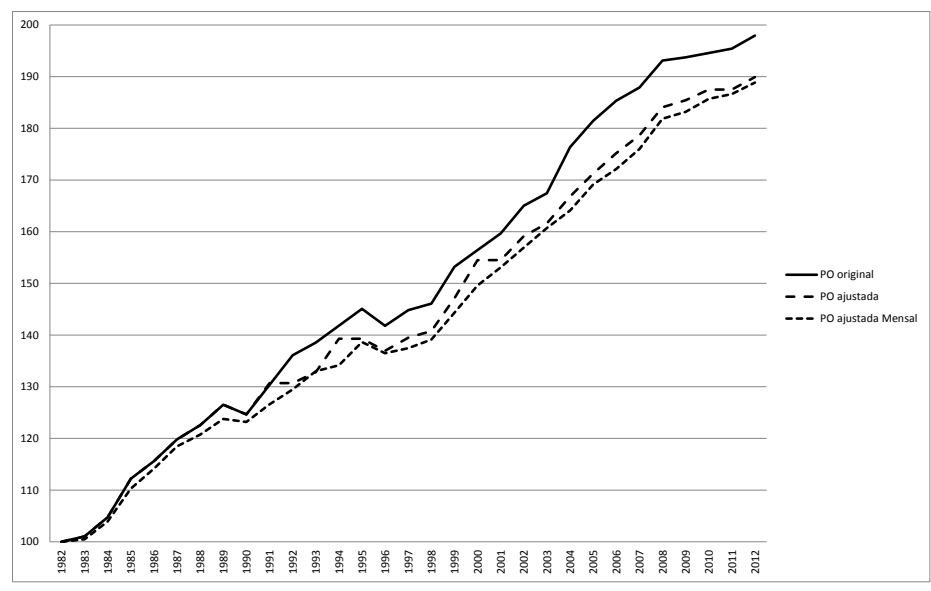

Fonte: Elaboração Própria.

\footnotetext{
${ }^{22}$ Retirou-se indivíduos que exerceram trabalho para o próprio consumo ou na construção para uso próprio inferior a 15 horas semanais. Esses indivíduos não foram considerados como ocupados.
} 
A Figura 5 mostra resultado similar da Figura 4 para as três séries do total de horas trabalhadas. A comparação entre a Figura 4 a e Figura 5 mostra que o nível das séries de horas trabalhadas é inferior ao das séries de pessoal ocupado devido à redução da jornada.

Figura 5: Séries de Horas Trabalhadas

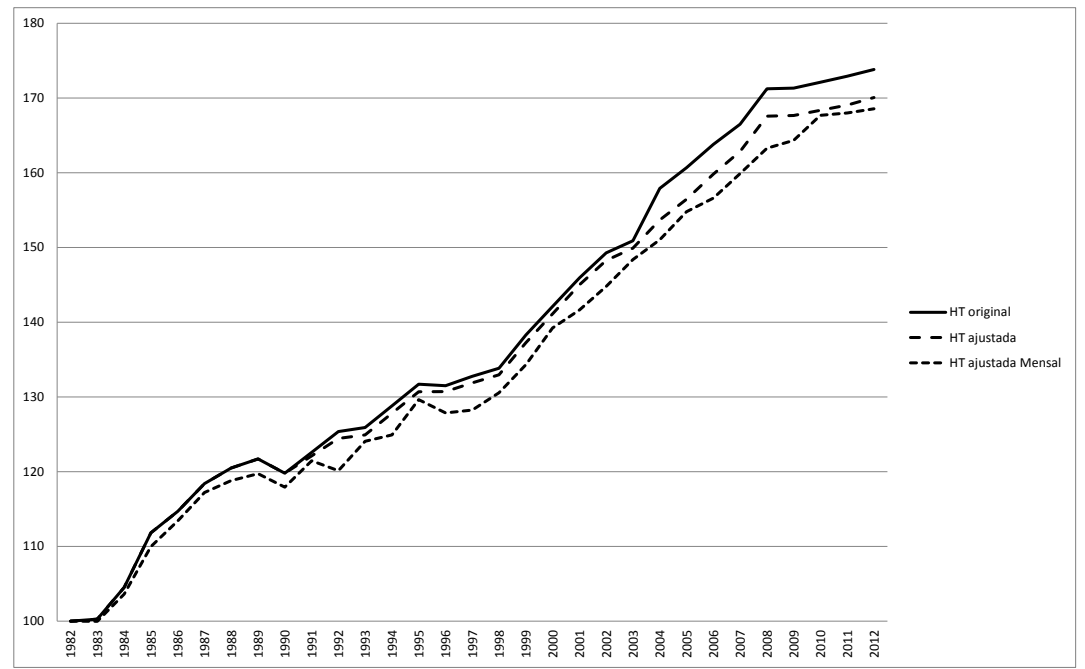

Fonte: Elaboração Própria.

\subsection{Produtividade do Trabalho}

A grande queda na jornada de trabalho entre 1982 e 1992 e a pequena redução ocorrida nas décadas seguintes fez com que dividíssemos a análise em três períodos distintos: 1982-1992, 1992-2002 e 20022012.

A Tabela 6 compara os resultados do cálculo da produtividade do trabalho com pessoal ocupado e com horas trabalhadas com os dados originais, ajustados da PNAD e mensais ajustados da PNAD. Os resultados da Tabela 4 mostram de forma inequívoca a importância de se analisar a produtividade com base nas horas trabalhadas em vez de utilizar o pessoal ocupado.

A comparação dos dados originais ( $2^{a}$ e $3^{a}$ colunas) e ajustados da PNAD ( $4^{a}$ e $5^{a}$ colunas) mostra que, no período entre 1982 e 1992, a diferença entre a produtividade do trabalho com base no pessoal ocupado (PTPO) e a baseada no total de horas trabalhadas (PTHT) foi de 7,6 pontos com os dados originais e de 4,7 pontos com os dados ajustados. Essa diferença aumenta somente 2,7 pontos para ambas as séries entre 1992 e 2002 . Entre 2002 e 2012 ocorre outro avanço nesse diferencial de 4,8 e 11,8 para diferenças respectivas de 15,1 e 19,2 pontos entre 2002 e 2011. Esses resultados indicam que a perda de produtividade durante a década perdida foi um efeito predominante da utilização do pessoal ocupado (não ajustado), sendo constatada baixa queda na produtividade hora do trabalho. 
Tabela 6: Produtividade do Trabalho com os Dados Originais e Ajustados da PNAD

\begin{tabular}{|c|c|c|c|c|c|c|}
\hline & \multicolumn{2}{|c|}{ Dados Originais da PNAD } & \multicolumn{2}{|c|}{ Dados Ajustados da PNAD } & \multicolumn{2}{|c|}{ Dados Ajustados Mensais da PNAD } \\
\hline & $\mathrm{PT}(\mathrm{PO})$ & $\mathrm{PT}(\mathrm{HT})$ & PT (PO) & $\mathrm{PT}(\mathrm{HT})$ & PT (PO) & $\mathrm{PT}(\mathrm{HT})$ \\
\hline 1982 & 100,0 & 100,0 & 100,0 & 100,0 & 100,0 & 100,0 \\
\hline 1983 & 96,1 & 96,8 & 96,1 & 96,8 & 96,6 & 97,1 \\
\hline 1984 & 97,7 & 97,9 & 97,7 & 97,9 & 98,4 & 98,8 \\
\hline 1985 & 98,3 & 98,7 & 98,3 & 98,7 & 100,0 & 100,3 \\
\hline 1986 & 102,6 & 103,4 & 102,6 & 103,4 & 103,9 & 104,6 \\
\hline 1987 & 102,5 & 103,7 & 102,5 & 103,7 & 103,7 & 104,8 \\
\hline 1988 & 100,1 & 101,9 & 100,1 & 101,9 & 101,6 & 103,3 \\
\hline 1989 & 100,1 & 104,0 & 100,1 & 104,0 & 102,3 & 105,7 \\
\hline 1990 & 97,2 & 101,1 & 97,2 & 101,1 & 98,3 & 102,7 \\
\hline 1991 & 93,8 & 99,8 & 95,8 & 100,2 & 96,6 & 100,7 \\
\hline 1992 & 89,5 & 97,1 & 93,2 & 97,9 & 94,1 & 101,4 \\
\hline 1993 & 92,0 & 101,2 & 96,0 & 102,0 & 95,8 & 102,7 \\
\hline 1994 & 94,7 & 104,2 & 98,7 & 105,0 & 100,1 & 107,5 \\
\hline 1995 & 96,6 & 106,4 & 100,6 & 107,3 & 101,1 & 108,1 \\
\hline 1996 & 101,0 & 108,9 & 104,6 & 109,5 & 104,9 & 112,0 \\
\hline 1997 & 102,2 & 111,5 & 106,1 & 112,3 & 107,7 & 115,4 \\
\hline 1998 & 101,4 & 110,6 & 105,2 & 111,4 & 106,4 & 113,4 \\
\hline 1999 & 96,9 & 107,4 & 100,9 & 108,2 & 102,9 & 110,5 \\
\hline 2000 & 99,0 & 109,0 & 102,7 & 109,7 & 103,5 & 111,2 \\
\hline 2001 & 98,3 & 107,5 & 101,5 & 108,2 & 102,5 & 110,8 \\
\hline 2002 & 97,6 & 107,9 & 101,2 & 108,6 & 102,6 & 111,2 \\
\hline 2003 & 97,3 & 108,0 & 100,8 & 108,7 & 101,4 & 109,8 \\
\hline 2004 & 97,6 & 109,1 & 103,2 & 112,1 & 104,9 & 114,0 \\
\hline 2005 & 97,9 & 110,6 & 103,8 & 113,6 & 105,0 & 114,8 \\
\hline 2006 & 99,6 & 112,8 & 105,4 & 115,6 & 107,3 & 117,9 \\
\hline 2007 & 104,3 & 117,7 & 109,7 & 120,3 & 111,3 & 122,5 \\
\hline 2008 & 106,7 & 120,3 & 111,9 & 123,0 & 113,3 & 126,2 \\
\hline 2009 & 106,0 & 119,9 & 110,8 & 122,5 & 112,1 & 125,0 \\
\hline 2010 & 113,5 & 128,3 & 118,4 & 131,2 & 118,9 & 131,7 \\
\hline 2011 & 116,1 & 131,2 & 121,0 & 134,2 & 121,6 & 135,1 \\
\hline 2012 & 110,5 & 126,6 & 115,2 & 134,6 & 121,2 & 135,8 \\
\hline
\end{tabular}

Fonte: Elaboração Própria.

A utilização das séries ajustadas mensais mostra que, entre 1982 e 1992, houve estagnação da produtividade hora do trabalho, aumento de $1,4 \%$ em dez anos, em vez de redução da produtividade. Com base no pessoal ocupado, observamos um resultado distinto, com redução de 5,9\% na produtividade em 10 anos em vez dos $11 \%$ de queda com base nos dados originais da PNAD. Desta forma, o restante da análise nesse artigo utiliza os resultados baseados nos dados mensais ajustados.

A Tabela 6 mostra que a produtividade do trabalho apresentou estagnação na década de oitenta, teve leve aumento nos anos noventa e acelerou o ritmo de crescimento a partir de 2004. Esse resultados indicam que o maior crescimento do PIB brasileiro a partir de 2004 foi um evento no qual a evolução da produtividade foi importante.

Seguindo essa linha de análise, realiza-se uma decomposição do crescimento do produto conforme as equações (9) e (10). A produtividade do trabalho baseada no pessoal ocupado (PTPO) pode ser decomposta em dois componentes: produtividade hora do trabalho (PTHT) e jornada média. ${ }^{23}$

A Tabela 7 mostra que na década perdida (1982-1992) a produtividade do trabalho teria caído 0,6\% ao ano quando calculada com base no pessoal ocupado. No entanto, essa queda é fruto da redução da jornada de trabalho que caiu $0,7 \%$ a.a. enquanto que a produtividade hora do trabalho subiu $0,1 \%$ a.a. Dessa forma, o crescimento do produto foi atribuído a expansão do pessoal ocupado de $2,6 \%$ no período.

\footnotetext{
${ }^{23} \mathrm{~A}$ produtividade do trabalho baseada no pessoal ocupado pode ser escrita da seguinte forma: $P T P O_{t}=\frac{P I B_{t}}{P O_{t}}=\frac{P I B_{t}}{H T_{t}} \times$ $\frac{H T_{t}}{P O_{t}}=P T H T_{t} \times J T_{t}$.
} 
Tabela 7: Decomposição do Crescimento

\begin{tabular}{|c|c|c|c|c|c|}
\hline & \multirow{2}{*}{ PIB } & \multicolumn{3}{|c|}{ Produtividade PO } & \multirow{2}{*}{ Pessoal Ocupado } \\
\hline & & Produtividade HT & Jornada média & Total & \\
\hline \multirow{2}{*}{ 1982-1992 } & \multirow{2}{*}{$2,0 \%$} & $0,1 \%$ & $-0,7 \%$ & $-0,6 \%$ & $2,6 \%$ \\
\hline & & $6,9 \%$ & $-38,0 \%$ & $-31,1 \%$ & $131,1 \%$ \\
\hline \multirow{2}{*}{$1992-2002$} & \multirow{2}{*}{$2,8 \%$} & $0,9 \%$ & $-0,1 \%$ & $0,8 \%$ & $1,9 \%$ \\
\hline & & $33,2 \%$ & $-2,0 \%$ & $31,2 \%$ & $68,8 \%$ \\
\hline $2002-2012$ & $3,5 \%$ & $2,0 \%$ & $-0,3 \%$ & $1,7 \%$ & $1,9 \%$ \\
\hline \multirow{2}{*}{$1982-2012$} & \multirow{2}{*}{$2,8 \%$} & $1,0 \%$ & $-0,4 \%$ & $0,6 \%$ & $2,1 \%$ \\
\hline & & $36,9 \%$ & $-13,7 \%$ & $23,2 \%$ & $76,8 \%$ \\
\hline \multirow{2}{*}{$1982-1990$} & \multirow{2}{*}{$2,4 \%$} & $0,3 \%$ & $-0,5 \%$ & $-0,2 \%$ & $2,6 \%$ \\
\hline & & $13,9 \%$ & $-22,8 \%$ & $-8,9 \%$ & $108,9 \%$ \\
\hline
\end{tabular}

Fonte: Elaboração Própria.

Na década seguinte, a produtividade hora do trabalho acelerou a sua taxa de crescimento para $0,9 \%$ a.a., enquanto que a redução da jornada de trabalho foi de somente $0,1 \%$ ao ano. A menor expansão do pessoal ocupado ( $1,8 \%$ a.a.) reduziu a importância do mesmo no período. Entretanto, continuou sendo o principal componente que explica o crescimento do período.

A aceleração da produtividade entre 2002 e 2012 foi fruto de ganho de produtividade dos trabalhadores, com somente uma parte sendo "perdida" com a redução da jornada de trabalho. Nesse período, o ganho de produtividade chega a explicar mais de $50 \%$ do crescimento do produto (a expansão do pessoal ocupado explica outra metade). O maior crescimento do PIB nesse período (3,5\% ao ano) é em grande parte explicado pelo crescimento robusto da produtividade.

No período como um todo, parte substancial dos ganhos de produtividade por hora de trabalho ( $0,9 \%$ a.a.) foi "perdida" com a redução da jornada de trabalho $(-0,4 \%$ a.a.), gerando um ganho de produtividade do trabalho de somente $0,5 \%$ a.a. Dessa forma, o ganho de produtividade explicou somente $20 \%$ do crescimento do produto (a expansão do fator trabalho explica $80 \%$ ).

Por último, as duas últimas linhas da Tabela 7 reforçam a leitura de que na década perdida não houve queda de produtividade. A redução da produtividade hora do trabalho entre 1982 e $1990^{24}$ foi fruto da redução da jornada de trabalho $(-0,5 \%$ a.a.) enquanto que a produtividade hora do trabalho aumentou $0,3 \%$ no período.

\subsection{Produtividade Total dos Fatores}

Assim como realizado com a produtividade do trabalho a produtividade total dos fatores (PTF) será computada com base no pessoal ocupado ( $\mathrm{PTF}(\mathrm{PO})$ ) e no total de horas trabalhadas (PTF(HT)). Este procedimento é importante, pois, como visto anteriormente, a elevação do pessoal ocupado foi maior do que a das horas trabalhadas, principalmente na década de oitenta, o que afeta a mensuração da PTF. Adicionalmente, assim como realizado na seção anterior apresentamos os resultados com base nos dados originais, ajustados e ajustados mensais da PNAD.

A Tabela 8 apresenta a PTF calculada entre 1982 e 2012. Os resultados mostram que existe uma diferença substancial na PTF calculada com base no pessoal ocupado e nas horas totais em virtude da forte redução da jornada de trabalho ocorrida na década de oitenta. Logo, a PTF baseada no pessoal ocupado subestima a evolução da produtividade no período.

\footnotetext{
${ }^{24}$ Entre 1982 e 1990 não há mudanças metodológicas na PNAD.
} 
A Tabela 8 mostra que a PTF (HT) seria, em 1992, 5 pontos superior à calculada com pessoal ocupado utilizando os dados originais da PNAD. Assim como ocorre com a produtividade do trabalho, as diferenças de produtividade nas décadas seguintes são menores em virtude de a redução da jornada de trabalho no período ser mais suave. Mesmo assim, a diferença fica superior aos dez pontos em 2012.

A diferença de valores da produtividade sugere que o peso dado à produtividade na descrição dos problemas de desempenho da economia ao longo da "década perdida" foi maior do que a mesma teria tido caso mensurada levando-se em conta as horas trabalhadas em vez do pessoal ocupado. A Tabela 8 mostra, ainda, que a perda de produtividade entre 1982 e 1992 seria de somente 4,5 pontos com o ajuste metodológico da PNAD e de somente $2,4 \%$ com base nos dados com ajuste mensal. Isso corresponde a uma perda de PTF de somente $0,24 \%$ a.a. em vez de perda superior a $0,5 \%$ a.a.

Tabela 8: Produtividade do Total dos Fatores (PTF) com os Dados Originais e Ajustados da PNAD

\begin{tabular}{|c|c|c|c|c|c|c|}
\hline & \multicolumn{2}{|c|}{ Dados Originais da PNAD } & \multicolumn{2}{|c|}{ Dados Ajustados da PNAD } & \multicolumn{2}{|c|}{ Dados Ajustados Mensais da PNAD } \\
\hline & PTF (PO) & $\mathrm{PTF}(\mathrm{HT})$ & PTF (PO) & $\mathrm{PTF}(\mathrm{HT})$ & PTF (PO) & PTF(HT) \\
\hline 1982 & 100,0 & 100,0 & 100,0 & 100,0 & 100,0 & 100,0 \\
\hline 1983 & 96,1 & 96,6 & 96,1 & 96,6 & 96,4 & 96,7 \\
\hline 1984 & 97,2 & 97,3 & 97,2 & 97,3 & 97,6 & 97,8 \\
\hline 1985 & 97,6 & 97,8 & 97,6 & 97,8 & 98,6 & 98,8 \\
\hline 1986 & 99,4 & 99,9 & 99,4 & 99,9 & 100,2 & 100,6 \\
\hline 1987 & 99,7 & 100,5 & 99,7 & 100,5 & 100,4 & 101,1 \\
\hline 1988 & 97,6 & 98,7 & 97,6 & 98,7 & 98,5 & 99,5 \\
\hline 1989 & 96,8 & 99,1 & 96,8 & 99,1 & 98,1 & 100,1 \\
\hline 1990 & 94,3 & 96,6 & 94,3 & 96,6 & 95,0 & 97,5 \\
\hline 1991 & 92,6 & 96,1 & 93,8 & 96,3 & 94,2 & 96,6 \\
\hline 1992 & 90,5 & 95,1 & 92,8 & 95,5 & 93,3 & 97,6 \\
\hline 1993 & 90,9 & 96,3 & 93,3 & 96,8 & 93,2 & 97,2 \\
\hline 1994 & 92,2 & 97,7 & 94,5 & 98,2 & 95,3 & 99,5 \\
\hline 1995 & 92,8 & 98,3 & 95,1 & 98,8 & 95,3 & 99,2 \\
\hline 1996 & 95,6 & 100,0 & 97,6 & 100,4 & 97,8 & 101,7 \\
\hline 1997 & 95,9 & 101,0 & 98,1 & 101,5 & 99,0 & 103,2 \\
\hline 1998 & 95,4 & 100,6 & 97,6 & 101,0 & 98,3 & 102,1 \\
\hline 1999 & 92,8 & 98,7 & 95,1 & 99,1 & 96,2 & 100,4 \\
\hline 2000 & 93,9 & 99,5 & 96,0 & 99,9 & 96,5 & 100,7 \\
\hline 2001 & 93,6 & 98,8 & 95,5 & 99,2 & 96,0 & 100,6 \\
\hline 2002 & 94,0 & 99,8 & 96,0 & 100,2 & 96,8 & 101,6 \\
\hline 2003 & 93,1 & 99,1 & 95,1 & 99,5 & 95,4 & 100,1 \\
\hline 2004 & 93,8 & 100,3 & 97,0 & 101,9 & 98,0 & 103,0 \\
\hline 2005 & 94,3 & 101,4 & 97,6 & 103,0 & 98,3 & 103,7 \\
\hline 2006 & 96,1 & 103,5 & 99,4 & 105,0 & 100,5 & 106,3 \\
\hline 2007 & 99,4 & 106,9 & 102,4 & 108,3 & 103,4 & 109,5 \\
\hline 2008 & 101,6 & 109,2 & 104,5 & 110,6 & 105,3 & 112,3 \\
\hline 2009 & 102,1 & 109,9 & 104,8 & 111,3 & 105,5 & 112,6 \\
\hline 2010 & 105,9 & 114,0 & 108,6 & 115,5 & 108,9 & 115,8 \\
\hline 2011 & 107,2 & 115,3 & 109,9 & 116,9 & 110,2 & 117,3 \\
\hline 2012 & 105,6 & 114,2 & 108,3 & 115,7 & 108,6 & 116,3 \\
\hline
\end{tabular}

Fonte: Elaboração Própria. 
A Tabela 9 mostra os resultados da decomposição do crescimento conforme a equação (13). A decomposição do crescimento mostra que, a $\mathrm{PTF}(\mathrm{PO})$ teria contribuído com $-35,2 \%$ para o crescimento entre 1982 e 2002 devido a uma queda de $0,7 \%$ ao ano na PTF. Entretanto, a utilização do total de horas trabalhadas (em vez de pessoal ocupado) mostra que a PTF(HT) teria uma retração de somente $0,2 \%$ ao ano e teria contribuído com $-12,4 \%$ do crescimento do produto, resultado ainda ruim, porém menos dramático.

A utilização das horas trabalhadas aumenta também a importância relativa da acumulação de capital na década de oitenta na explicação do crescimento do produto, que passa a ser mais importante do que o aumento do fator trabalho.

Tabela 9: Decomposição do Crescimento

\begin{tabular}{|c|c|c|c|c|c|}
\hline & PIB & PTF(PO) & Capital & NUCI & PO \\
\hline \multirow{2}{*}{$1982-1900$} & \multirow{2}{*}{$2,4 \%$} & $-0,6 \%$ & $1,4 \%$ & $0,1 \%$ & $1,6 \%$ \\
\hline & & $-26,7 \%$ & $-59,1 \%$ & $-2,3 \%$ & $-65,4 \%$ \\
\hline \multirow{2}{*}{ 1982-1992 } & \multirow{2}{*}{$2,0 \%$} & $-0,7 \%$ & $1,3 \%$ & $-0,2 \%$ & $1,5 \%$ \\
\hline & & $-35,2 \%$ & $-65,9 \%$ & $-9,4 \%$ & $-78,6 \%$ \\
\hline \multirow{2}{*}{ 1992-2002 } & \multirow{2}{*}{$2,8 \%$} & $0,4 \%$ & $0,9 \%$ & $0,4 \%$ & $1,2 \%$ \\
\hline & & $-13,3 \%$ & $-32,0 \%$ & $-13,4 \%$ & $-41,3 \%$ \\
\hline \multirow{2}{*}{ 2002-2012 } & \multirow{2}{*}{$3,5 \%$} & $1,1 \%$ & $1,0 \%$ & $0,2 \%$ & $1,1 \%$ \\
\hline & & $-32,7 \%$ & $-29,7 \%$ & $-6,0 \%$ & $-31,6 \%$ \\
\hline \multirow{3}{*}{ 1982-2012 } & \multirow{2}{*}{$2,8 \%$} & $0,3 \%$ & $1,1 \%$ & $0,1 \%$ & $1,3 \%$ \\
\hline & & $-10,0 \%$ & $-39,1 \%$ & $-4,8 \%$ & $-46,1 \%$ \\
\hline & PIB & PTF(HT) & Capital & NUCI & HT \\
\hline \multirow{2}{*}{$1982-1900$} & \multirow{2}{*}{$2,4 \%$} & $-0,3 \%$ & $1,4 \%$ & $0,1 \%$ & $1,2 \%$ \\
\hline & & $-13,1 \%$ & $-59,1 \%$ & $-2,3 \%$ & $-51,7 \%$ \\
\hline \multirow{2}{*}{ 1982-1992 } & \multirow{2}{*}{$2,0 \%$} & $-0,2 \%$ & $1,3 \%$ & $-0,2 \%$ & $1,1 \%$ \\
\hline & & $-12,4 \%$ & $-65,9 \%$ & $-9,4 \%$ & $-55,8 \%$ \\
\hline \multirow{2}{*}{ 1992-2002 } & \multirow{2}{*}{$2,8 \%$} & $0,4 \%$ & $0,9 \%$ & $0,4 \%$ & $1,1 \%$ \\
\hline & & $-14,5 \%$ & $-32,0 \%$ & $-13,4 \%$ & $-40,1 \%$ \\
\hline \multirow{2}{*}{$2002-2012$} & \multirow{2}{*}{$3,5 \%$} & $1,3 \%$ & $1,0 \%$ & $0,2 \%$ & $0,9 \%$ \\
\hline & & $-38,3 \%$ & $-29,7 \%$ & $-6,0 \%$ & $-26,0 \%$ \\
\hline \multirow{2}{*}{$1982-2012$} & \multirow{2}{*}{$2,8 \%$} & $0,5 \%$ & $1,1 \%$ & $0,1 \%$ & $1,0 \%$ \\
\hline & & $-18,2 \%$ & $-39,1 \%$ & $-4,8 \%$ & $-37,8 \%$ \\
\hline
\end{tabular}

Fonte: Elaboração Própria.

O mesmo fenômeno ocorre em menor grau para os períodos seguintes. A produtividade mostra recuperação entre 1992 e 2002 e entre 2002 e 2012. Em ambos períodos ocorre um pequeno ganho da importância da produtividade no cálculo com horas trabalhadas. $\mathrm{O}$ ganho de produtividade entre 2002 e 2012 foi o principal elemento explicando o crescimento do produto no período. A ampliação do fator trabalho é o que mais contribui para a elevação do produto nas décadas de oitenta e noventa. Porém, quando utilizada a ampliação das horas de trabalho, a magnitude da contribuição do capital e do trabalho são similares (em torno de 30\%) na década 1992-2002.

No período como um todo, entre 1982 e 2012, observa-se que a produtividade contribuiu com cerca de $10,0 \%$ do crescimento, utilizando o pessoal ocupado, e com $18,2 \%$ utilizando o total de horas trabalhadas. $O$ crescimento da produtividade aumenta de $0,3 \%$ ao ano para $0,5 \%$ com a utilização do total de horas trabalhadas, embora ainda seja um crescimento medíocre.

o trabalho mostra ainda que para o período entre 1982 e 2012, o crescimento das horas trabalhadas contribui com $1,1 \%$ para o crescimento do produto. O crescimento do capital por sua vez contribuiu para um máximo de $1,3 \%$ ao ano na década de oitenta e $1,1 \%$ ao ano no período como um todo, o que representa uma acumulação média de capital de $2,7 \%$ ao ano. 


\section{CONCLUSÃO}

O presente artigo contribui para a literatura ao calcular séries de produtividade para a economia brasileira com base nas horas trabalhadas em vez de pessoal ocupada entre 1982 e 2012. O trabalho documenta que houve redução da jornada de trabalho no período. Dessa forma, cálculos de produtividade baseados em séries de pessoal ocupado subestimam a taxa de crescimento da produtividade no Brasil, principalmente na década de oitenta, período de maior queda da jornada média de trabalho.

O trabalho construiu uma série de horas trabalhadas em frequência mensal a partir de 1982, utilizando dados de horas trabalhadas e pessoal ocupado das metodologias nova e antiga da Pesquisa Mensal de Emprego (PME) do IBGE e dados da Pesquisa Nacional por Amostra de Domicílios (PNAD). Os resultados indicam que a série de horas trabalhadas mensal ajustada cresceu $20,6 \%$ a menos do que a série de pessoal ocupado mensal ajustada no período analisado, entre 1982 e 2012.

A maior expansão da população ocupada em relação ao total de horas trabalhadas é explicada pela redução da jornada média de trabalho, ocorrida em sua maior parte na década de oitenta, quando a diferença entre as duas séries foi de $6,3 \%$. O trabalho documenta que essa redução mais forte ocorreu após a Constituição de 1988, período em que o percentual de trabalhadores com jornada superior a 44 horas semanais em relação à população ocupada se reduziu.

Por último, o artigo permite releitura da evolução da produtividade nas últimas três décadas no Brasil e apresenta uma análise distinta da usualmente reportada na literatura. A queda da produtividade do trabalho observada na década perdida foi fruto da redução da jornada média de trabalho e não redução da produtividade hora da economia. O uso do total de horas trabalhadas no cálculo de decomposição de crescimento resulta que a PTF do período caiu menos do que o relatado em diversos trabalhos na literatura.

Os resultados mostram que, no período 1982-2012, a produtividade do trabalho aumentou $21,2 \%$ com base no pessoal ocupado e $35,8 \%$ com no total de horas trabalhadas, uma diferença de 14,6 pontos percentuais. A maior parte dessa diferença (7,3 p.p.) surgiu entre 1982 e 1992, período no qual houve a maior redução da jornada de trabalho. Ou seja, entre 1982 e 1992 houve uma estagnação na produtividade por hora trabalhada, que cresceu $0,1 \%$ a.a., mas o ajuste na margem intensiva (jornada média de trabalho) contribuiu com uma redução de $0,7 \%$ ao ano na produtividade do trabalhador ocupado, que registrou redução de $0,6 \%$ a.a.

A produtividade total dos fatores calculada com base no pessoal ocupado (PTF(PO)) também é inferior à calculada com base no total de horas trabalhadas $(\operatorname{PTF}(\mathrm{HT}))$. Entre 1982 e 1992, a $\operatorname{PTF}(\mathrm{HT})$ é 4,3 p.p. superior à $\mathrm{PTF}(\mathrm{PO})$, com essa diferença atingindo 7,7 p.p. em 2012. Isso significa que, enquanto a PTF(PO) explica somente 10,0\% da expansão de renda entre 1982 e 2012, a PTF(HT) explica 18,2\% do aumento do PIB no período. Logo, ao analisar períodos mais longos as diferenças na forma de estimação da produtividade implicam diferenças significativas na importância dos fatores que explicam o crescimento econômico.

\section{BIBLIOGRAFIA}

Alesina, A.; Glaesar, E. \& Sacerdote, B. (2006). Work and Leisure in the U.S. and Europe: Why is so different? Technical Report 20, NBER Macroeconomics Annual.

Barbosa Filho, F. \& de Abreu Pessôa, S. (2009). Série de Horas Mensais da Economia Brasileira. Technical report, nota Técnica do IBRE.

Bonelli, R. (2002). Labor Productivity in Brazil during the 90s. Technical Report 906, Texto para Discussão do IPEA.

Bonelli, R. \& Fonseca, R. (1998). Ganhos de Produtividade e de Eficiência: Novos Resultados para a Economia Brasileira. Technical Report 557, Texto para Discussão do IPEA. 
Coleman, M. T. \& Pencavel, J. (1993a). Changes in Work Hours of Male Employees, 1940-1988. Industrial and Labor Relations Review, 46(2):262-283.

Coleman, M. T. \& Pencavel, J. (1993b). Trends in Market Work Behavior of Women since 1940. Industrial and Labor Relations Review, 46(4):653-676.

Ellery Jr., R. \& Teixeira, A. (2013). O Milagre, a Estagnação e a Retomada do Crescimento: As Lições da Economia Brasileira nas Últimas Décadas. In Em Desenvolvimento Econômico. Uma Perspectiva Brasileira de Veloso, F, Ferreira, P., Giambiagi, F. e Pessôa, S.

Ferreira, P. \& Rossi, J. (2003). New Evidence from Brazil on Trade Liberalizations and Productivity Growth. International Economic Review, 44(4):1383-1405.

Gomes, V., de Abreu Pessôa, S., \& Veloso, F. (2003). Evolução da Produtividade Total dos Fatores na Economia Brasileira: Uma Análise Comparativa. Pesquisa e Planejamento Econômico, 33(3):389-434.

Gonzaga, G., Menezes, F. N., \& Camargo, J. (2003). Os efeitos da redução da jornada de trabalho de 48 para 44 horas semanais em 1988. Revista Brasileira de Economia, 57:369-400.

Guerra, V. (1997). Principais Mudanças Introduzidas nos Conceitos e Definições da PNAD para as Pesquisas de 1992 em Diante. Mimeo.

Owen, J. (1988). Work-time Reduction in the United States and Western Europe. Technical report, Monthly Labor Review 111.

Prescott, E. (2004). Why do Americans Work so Much More than Europeans? Working Paper 10316, NBER. 